\title{
A STUDY OF EPICARDIAL ADIPOSE TISSUE (EAT) AND CAROTID INTIMA-MEDIA THICKNESS (CIMT) IN PATIENTS WITH AND WITHOUT ISCHAEMIC HEART DISEASE
}

\author{
Jayaram Vasu1, Cicy Bastian², Deepak Garg ${ }^{3}$ \\ ${ }^{1}$ Assistant Professor, Department of Cardiology, Government T. D. Medical College, Alappuzha. \\ ${ }^{2}$ Associate Professor, Department of Cardiology, Government T. D. Medical College, Alappuzha. \\ ${ }^{3}$ Senior Resident, Department of Cardiology, Government T. D. Medical College, Alappuzha.
}

\begin{abstract}
\section{BACKGROUND}

Early diagnosis can be an important measure to reduce the CAD-related morbidity and mortality. Carotid intima-media thickness (CIMT) is one such measure which has been validated as a surrogate marker for subclinical atherosclerosis and is used for early detection of accelerated disease process and subclinical disease. Over the past decade, epicardial fat thickness has generated interest as a marker for atherosclerosis, after being found to have a strong association with visceral obesity. At the same time, other studies have questioned the association. There is paucity of data for epicardial fat thickness as a marker for atherosclerosis in Indian population. This study tries to explore the relationship between coronary artery disease and the two markers of atherosclerosis- Carotid intima-media thickness and Epicardial Fat.
\end{abstract}

\section{MATERIAL AND METHODS}

500 study subjects each, were enrolled under two groups of cases and controls, after coronary angiogram, depending on presence of either normal epicardial coronaries (no CAD- Group 1) which was the control group or significant CAD (Group 2) which was the case group. EAT (Epicardial Adipose Tissue) thickness and CIMT were measured.

\section{RESULTS}

Group 1 subjects (no CAD) had a median age of $52.84 \pm 9.39$ years, with $62.4 \%$ males, and Group 2 (CAD) had a median age of $55.22 \pm 9.16$ years with $84 \%$ males. On multiple regression analysis, male sex, age, total cholesterol, HDL, LDL, waist circumference and hip circumference were found to be significant predictors of CAD. Mean epicardial fat thickness differed significantly between the two groups $(\mathrm{p}<0.001)$, whereas the difference in CIMT between the two groups was not statistically significant. On comparison of EAT thickness quartiles with Gensini score, EAT thickness did not increase with increasing severity of CAD.

\section{CONCLUSION}

Our study shows that increased EAT thickness is associated with significant epicardial obstructive CAD. Epicardial fat thickness, but not CIMT, can differentiate patients with CAD among a population of patients with coronary risk factors and suspected CAD. Epicardial fat thickness did not increase with increasing severity of CAD.

\section{KEYWORDS}

Carotid intima-media thickness, Epicardial Fat, Coronary Artery Disease.

HOW TO CITE THIS ARTICLE: Vasu J, Bastian C, Garg D. A study of epicardial adipose tissue (EAT) and carotid intima-media thickness (CIMT) in patients with and without ischaemic heart disease. J. Evolution Med. Dent. Sci. 2017;6(81):5724-5728, DOI: $10.14260 /$ jemds/2017/1241

\section{BACKGROUND}

Coronary Artery Disease (CAD) is amongst the major causes of morbidity and mortality in the developed and developing countries alike, so much so that it still accounts for almost one-third of all mortalities in population more than 35 years of age. ${ }^{1}$ The lifetime risk of developing CAD in population reaching 70 years is 35 percent in men and 24 percent in women, with the same as high as 49 percent in men and 32 percent in women, aged 40 years. ${ }^{2}$

'Financial or Other Competing Interest': None.

Submission 04-08-2017, Peer Review 27-09-2017,

Acceptance 03-10-2017, Published 09-10-2017.

Corresponding Author:

Dr. Deepak Garg,

Senior Resident,

Department of Cardiology,

J-Block, TDMCH, Vandanam-688005,

Alappuzha, Kerala.

E-mail: deepaksir1985@yahoo.in

DOI: $10.14260 /$ jemds $/ 2017 / 1241$
CAD burden is higher in the Indian subcontinent compared to most populations of the world. Whereas CAD prevalence was reported to be $7.3 \%$ in the US in 2005.1 Indian studies estimated the prevalence to be $7 \%$ in rural India and as high as $11 \%$ in the urban Indian population. ${ }^{3,4}$

Higher CAD burden in India is accounted for by the large population, higher prevalence of the traditional CAD risk factors and the rapid increase in urban population, resulting in the early onset of obesity, hypertension and dyslipidaemias. ${ }^{5}$ All risk factors traditionally associated with CAD are considerably more prevalent in the Indian subcontinent including diabetes, hypertension, dyslipidaemias, smoking, metabolic syndrome and CKD. ${ }^{5}$ In addition, studies over the last decade suggest that South Asian ethnicity itself may be an additional risk factor independent of other risk factors. ${ }^{6}$

Early diagnosis and management of CAD is important in the attempt to reduce the CAD-related morbidity and mortality, which is often significant. Also, significant CAD can exist with minimal or no symptom and have rapid 
progression, manifesting first with ST elevation myocardial infarctions and sudden cardiac deaths. ${ }^{7}$

Clinical methods to assess subclinical atherosclerosis, play an important role in early identification and appropriate management of such at-risk patients. Early diagnosis thus achieved can be an important measure to reduce the CADrelated morbidity and mortality.

Carotid intima-media thickness (CIMT) is one such measure which has been validated as a surrogate marker for subclinical atherosclerosis and is used for early detection of accelerated disease process and subclinical disease. Measured with B mode ultrasound, it is non-invasive, inexpensive and easily repeatable tool for early diagnosis of accelerated atherosclerotic disease. ${ }^{8}$

Over the past decade, epicardial fat thickness has generated interest as a marker for atherosclerosis, after being found to have a strong association with visceral obesity. ${ }^{9}$ At the same time, other studies have questioned the significance of this association, if any. ${ }^{10,11}$

There is paucity of data for epicardial fat thickness as a marker for atherosclerosis in Indian population. A study from South India found excellent correlation between epicardial fat measured by echocardiography and anthropometric parameters of metabolic syndrome, in healthy patient population, ${ }^{12}$ but no such data exists in Indian patients with CAD.

This study tries to explore the relationship between coronary artery disease and the two markers of atherosclerosis- Carotid intima-media thickness and Epicardial Fat.

\section{MATERIALS AND METHODS}

This was a case-control study which included 1000 patients. Epicardial Adipose Tissue (EAT) and Carotid intima-media thickness (CIMT) was measured with ultrasonography in 500 consecutive patients attending Department of Cardiology, TDMCH, Alappuzha, who had angiographically normal coronary arteries and were considered controls, and 500 consecutive patients with significant CAD on angiogram which were considered as cases, between May 2014 and May 2016. The values were correlated with the presence or absence of CAD, severity of CAD by Gensini score, waist-hip ratio, $\mathrm{BMI}$ and other cardiovascular risk factors.

\section{There were Two Groups-}

Group 1 (controls) - Patients who had angiographically normal epicardial coronary arteries, or negative exercise stress test (Exercise up to Bruce Stage 3 without any significant ECG changes) and normal echocardiography.

Group 2 (cases) - Patients with angiographically proven significant ( $>50 \%$ left main, $\geq 70 \%$ others) epicardial coronary artery disease.

Patients between ages 30-70 years were included.

\section{Inclusion/Exclusion Criteria \\ Group 1 (Controls) \\ Inclusion Criteria}

1. Angiographically proven normal epicardial coronary arteries, Or Negative exercise stress test (Exercise up to Bruce Stage 3 without any significant ECG changes) and normal echocardiography.

2. Age between 30-70 years.

\section{Exclusion Criteria}

1. Patients who are admitted with severe heart failure.

2. $\mathrm{LVEF}<35 \%$.

3. Post CABG.

4. BMI of less than 18 and more than 40 .

5. Any Acute Myocardial Infarction (STEMI and NSTEMI) in the past.

6. Patients on Corticosteroids, Oestrogens, Tricyclic antidepressants, Monoamine oxidase inhibitors, Serotonin Reuptake Inhibitors, Antipsychotics, Lithium, Tamoxifen.

7. Pericardial Disease.

8. Cardiomyopathy (Restrictive, Hypertrophic or Dilated).

9. Inability to image CIMT or EAT due to suboptimal images.

\section{Group 2 (Cases)}

\section{Inclusion Criteria}

1. Angiographically proven significant (> 50\% left main, $\geq 70 \%$ others) epicardial Coronary Artery Disease.

2. Age 30-70 years.

\section{Exclusion criteria}

1. Patients who are admitted with severe heart failure.

2. $\mathrm{LVEF}<35 \%$.

3. Post CABG.

4. BMI of less than 18 and more than 40 .

5. Patients on Corticosteroids, Oestrogens, Tricyclic antidepressants, Monoamine oxidase inhibitors, Serotonin Reuptake Inhibitors, Antipsychotics, Lithium or Tamoxifen.

6. Pericardial Disease.

7. Cardiomyopathy (Restrictive, Hypertrophic or Dilated).

8. Tortuosity or aneurysm of abdominal aorta.

9. Inability to image CIMT or EAT due to suboptimal images.

\section{Epicardial Pad of FAT (EPF)}

EPF was measured using a GE Vivid E9 Ultrasound machine with a $5 \mathrm{MHz}$ transducer and digitally recorded. Epicardial fat thickness was measured on the free wall of the right ventricle at end-systole in 3 cardiac cycles in both parasternal long-and short-axis views. The maximum values at any site was measured, and the average value considered. The measurements were read in duplicate as per standard procedure independently by two different experienced echocardiographers.

\section{Carotid intima-media thickness (CIMT)}

The carotid arteries were imaged in the longitudinal section using a GE Vivid E9 Ultrasound machine with a $5 \mathrm{MHz}$ transducer and digitally recorded during the systole, for offline measurement. The IMT was measured on the far wall at $1 \mathrm{~cm}$ from bifurcation of the common carotid artery as the distance between the lumen-intima interface and the mediaadventitia interface. All measurements were made at a plaque-free site. The measurements were read in duplicate as per standard procedure independently by two different experienced echocardiographers. 
Assessment of CAD Severity- Gensini Score

Severity of CAD was assessed by Gensini scoring.

\section{Statistical Analysis}

The distribution of data on all categorical data related to subject's clinical variables was expressed as frequencies and percentages and the comparison between the groups was carried out by using $\chi 2$ or Fisher's exact test. The distribution of data on laboratory parameters was expressed as mean with SD or median with range whichever was appropriate. The comparison of data between the groups was carried out by using independent student's t test. Simple and multiple logistic regression analysis were used to identify the independent factors associated with CAD. All statistical analysis was carried out at $5 \%$ level of significance and a $\mathrm{P}$ value $<0.05$ was considered as significant.

\section{RESULTS}

Total of 1000 patients included in the study were divided, based on presence or absence of significant coronary artery disease, into 2 groups, no CAD (Group 1) and CAD (Group 2).

\begin{tabular}{|c|c|c|c|c|c|}
\hline & \multicolumn{4}{|c|}{ CAD } & \multirow{2}{*}{ I } \\
\cline { 2 - 5 } & \multicolumn{2}{|c|}{ No (Group 1) } & Yes (Group 2) & p value \\
\cline { 2 - 5 } & Median & IQR & Median & IQR & \\
\hline Age (Years) & 52.84 & 9.39 & 55.22 & 9.16 & 0.004 \\
\hline Males (n, \%) & $312(62.4)$ & - & $420(84)$ & - & $<0.001$ \\
\hline Weight (kg) & 67.86 & 10.66 & 70.45 & 9.15 & 0.004 \\
\hline Height (metres) & 1.66 & 0.07 & 1.70 & 0.06 & 0.007 \\
\hline BMI & 24.62 & 3.04 & 25.13 & 3.09 & 0.061 \\
\hline Waist (Inches) & 31.62 & 2.56 & 32.31 & 2.52 & 0.003 \\
\hline Hip (Inches) & 33.60 & 2.16 & 35.23 & 2.31 & $<0.001$ \\
\hline $\begin{array}{c}\text { Waist/Hip } \\
\text { (Ratio) }\end{array}$ & 0.94 & 0.07 & 0.92 & 0.06 & $<0.001$ \\
\hline Table 1. Dem & & & & & \\
\hline
\end{tabular}

Table 1. Demographic and Anthropometric Profiles of Both Groups

\begin{tabular}{|c|c|c|c|c|c|}
\hline & \multicolumn{4}{|c|}{ CAD } & \multirow{3}{*}{$\begin{array}{c}\mathbf{p} \\
\text { value }\end{array}$} \\
\hline & \multicolumn{2}{|c|}{ No (Group 1) } & \multicolumn{2}{|c|}{ Yes (Group 2) } & \\
\hline & Median & IQR & Median & IQR & \\
\hline $\begin{array}{c}\text { Hypertension } \\
(\mathrm{n} / \%)\end{array}$ & $187(37.4)$ & - & $213(42.6)$ & - & 0.235 \\
\hline $\begin{array}{l}\text { Diabetes } \\
(\mathrm{n} / \%)\end{array}$ & 109 (21.8) & - & 143 (28.6) & - & 0.079 \\
\hline $\begin{array}{l}\text { Family } \\
\text { history } \\
(\mathrm{n} / \%)\end{array}$ & $112(22.4)$ & - & $82(16.5)$ & - & 0.087 \\
\hline $\begin{array}{l}\text { Abd. Obesity } \\
\text { (n/\%) }\end{array}$ & $119(23.8)$ & - & $123(24.6)$ & - & 0.916 \\
\hline $\begin{array}{l}\text { Smoking } \\
(\mathrm{n} / \%)\end{array}$ & $163(32.6)$ & - & 147 (29.4) & - & 0.498 \\
\hline TC & 206.24 & 24.52 & 225.71 & 19.33 & $<0.001$ \\
\hline LDL & 123.51 & 24.52 & 141.31 & 19.84 & $<0.001$ \\
\hline HDL & 42.24 & 4.22 & 39.61 & 3.96 & $<0.001$ \\
\hline TG & 202.32 & 24.42 & 223.71 & 27.37 & $<0.001$ \\
\hline VLDL & 40.43 & 4.82 & 44.71 & 5.44 & $<0.001$ \\
\hline$T$ & $\begin{array}{r}\text { Corona } \\
\text { Prof } \\
\end{array}$ & Irtery & $\begin{array}{l}\text { isease Ri } \\
\text { Groups }\end{array}$ & acto & \\
\hline
\end{tabular}

Group 1 patients with normal coronaries had a Gensini score of 0 , whereas the median calculated Gensini score, in patients with CAD (Group 2) was $48.74 \pm 34.59$.

All metabolic parameters, including age, waist-hip ratio and lipid profile parameters were found significantly differing in the coronary artery disease group compared to the group 1 with normal coronary arteries.

\begin{tabular}{|c|c|c|c|c|c|}
\hline \multirow{4}{*}{} & \multicolumn{4}{|c|}{ CAD } & \multirow{2}{*}{ p value } \\
\cline { 2 - 5 } & \multicolumn{2}{|c|}{ No (Group 1) } & \multicolumn{2}{c|}{ Yes (Group 2) } & \\
\cline { 2 - 5 } & Median & IQR & Median & IQR & \\
\hline $\begin{array}{c}\text { CIMT Mean } \\
\text { R (Cm) }\end{array}$ & 0.062 & 0.014 & 0.061 & 0.012 & 0.733 \\
\hline $\begin{array}{c}\text { CIMT Mean } \\
\text { L (Cm) }\end{array}$ & 0.062 & 0.014 & 0.061 & 0.012 & 0.799 \\
\hline
\end{tabular}

Table 3. CIMT Comparison in Group 1 and 2

Median carotid intima-media thickness (CIMT) in group 1 was $0.062 \pm 0.014$ for 2 right as well as left carotid arteries. The same was $0.061 \pm 0.012$ in the group with CAD (group 2), with no statistical significance, at $\mathrm{p}=0.76$.

\begin{tabular}{|r|c|c|c|c|c|}
\hline \multirow{4}{*}{} & \multicolumn{4}{|c|}{ CAD } & \multirow{2}{*}{ p value } \\
\cline { 2 - 5 } & \multicolumn{2}{|c|}{ No } & \multicolumn{2}{c|}{ Yes } & \\
\cline { 2 - 5 } & Median & IQR & Median & IQR & \\
\hline EPI Mean LAX & 0.424 & 0.113 & 0.508 & 0.115 & $<0.001$ \\
\hline EPI Mean SAX & 0.422 & 0.114 & 0.508 & 0.115 & $<0.001$ \\
\hline Table 4. EAT Comparison in Both Groups \\
\hline
\end{tabular}

\begin{tabular}{|c|c|c|}
\hline & R & P value \\
\hline Age & 0.597 & $<0.001$ \\
\hline BMI & 0.279 & $<0.001$ \\
\hline Waist & 0.325 & $<0.001$ \\
\hline Waist/Hip & 0.096 & 0.031 \\
\hline TC & 0.182 & $<0.001$ \\
\hline HDL & -0.116 & 0.009 \\
\hline TG & 0.203 & $<0.001$ \\
\hline VLDL & 0.203 & $<0.001$ \\
\hline LDL & 0.157 & $<0.001$ \\
\hline Table 5. Correlation between Epicardial Thickness and \\
Clinical Parameter \\
\hline \multicolumn{3}{|c}{} \\
\hline
\end{tabular}

Amongst the clinical parameters of the patient population, age, BMI, waist, waist-hip ratio (WHR) had a significant positive association with epicardial adipose tissue thickness. All lipid parameters, total cholesterol, HDL, LDL, TG and VLDL were significantly associated with epicardial adipose tissue thickness. On multiple regression analysis of variables such as sex, age, total cholesterol, HDL, LDL, waist circumference, hip circumference, smoking, hypertension and family history - male sex, age, total cholesterol, HDL, LDL, waist circumference and hip circumference were independent predictors of significant CAD.

\begin{tabular}{|c|c|c|}
\hline & P value & OR (95 \% CI) \\
\hline Male sex & $<0.001$ & $3.32(1.88-5.89)$ \\
\hline Age (Years) & 0.005 & $1.04(1.01-1.06)$ \\
\hline TC & $<0.001$ & $1.27(1.19-1.35)$ \\
\hline HDL & $<0.001$ & $0.70(0.64-0.76)$ \\
\hline LDL & $<0.001$ & $0.82(0.78-0.87)$ \\
\hline Waist (Inches) & $<0.001$ & $0.81(0.72-0.91)$ \\
\hline Hip (Inches) & $<0.001$ & $1.62(1.40-1.87)$ \\
\hline
\end{tabular}

Table 6. Multiple Regression Analysis for Presence of Significant CAD

For analysing the relation, if any, between the extent of CAD (quantified by Gensini score) and epicardial fat thickness, the EAT thickness of group 2 patients was divided into quartiles. The quartiles were $\leq 0.43,>0.43-\leq 0.51,>0.51$ - 
$\leq 0.58$ and $>0.58$. Mean Gensini score, for quartile 1-4, were $48.69 \pm 34.25,50.25 \pm 38.31,47.93 \pm 33.95$ and $48.06 \pm$ 32.36 , respectively. The P value was 0.981 , overall.

\begin{tabular}{|c|c|c|c|c|}
\hline EAT (Mean SAX) & \multirow{2}{*}{ N } & \multicolumn{2}{|c|}{ Gensini score } & \multirow{2}{*}{ P value } \\
\cline { 3 - 4 } Quartiles & & Median & IQR & \\
\hline Q1 $(<=0.43)$ & 62 & 48.69 & 34.25 & \\
\hline Q2 $(>0.43-<=0.51)$ & 63 & 50.25 & 38.31 & \multirow{2}{*}{0.981} \\
\hline Q3 $(>0.51-<=0.58)$ & 61 & 47.93 & 33.95 & \\
\hline Q4 $(>0.58)$ & 64 & 48.06 & 32.36 & \\
\hline
\end{tabular}

Table 7. Correlation of Gensini Score with EAT Quartiles

\begin{tabular}{|c|c|c|}
\hline & $\begin{array}{c}\text { Correlation } \\
\text { coefficient (r) }\end{array}$ & P value \\
\hline CIMT mean & -0.056 & 0.376 \\
\hline Epi LAX mean & -0.039 & 0.537 \\
\hline Epi SAX mean & -0.039 & 0.537 \\
\hline Table 8. Pearson's Correlation Coefficient for CIMT and \\
EAT with Gensini Score \\
\hline
\end{tabular}

\section{DISCUSSION}

In this study, all the patients in both groups were patients undergoing coronary angiography for suspected CAD. In the present study, our group 2 (CAD) patient population had a mean age of $53.22 \pm 9.16$ years, which is almost a decade younger than the CAD population mean age groups in other studies (63-68 years). ${ }^{13,14}$ This is in parallel with the fact that CAD presents earlier in the south Asian population/subcontinent

In our study, the prevalence of diabetes was higher in both group 1 and 2 at $21.6 \%$ and $28.4 \%$, respectively, which is higher than the prevalence noted in studies from other parts of the world. 15,16

Epicardial fat measurement in group 1, with no CAD, was $0.42 \mathrm{~cm}$ and in the group 2 with CAD was significantly higher at $0.50 \mathrm{~cm}(\mathrm{p}<0.001)$. The values of epicardial fat thickness in our study appears to differentiate the groups with and without CAD. However, the values of epicardial fat in our study is much lower than the values elsewhere.13,15

Many of the studies done in the West had divided patients into groups based on epicardial fat thickness of $0.7 \mathrm{~cm}^{2}$, but in our analysis the mean EAT of group 1 (no CAD) was 0.42 $\mathrm{cm}$ and $0.52 \mathrm{~cm}$ for CAD group. When we looked at our data, we had only 12 patients who had EAT more than $0.7 \mathrm{~cm}$ in the CAD group, and no patients had EAT of more than $0.7 \mathrm{~cm}$ in the no-CAD group.

In our study, we compared the Gensini score to quartiles of epicardial adipose tissue. The Gensini score was not correlating with higher adipose tissue quartiles. This was in contradiction to the study by Maryam et $\mathrm{al}^{14}$ and Eroglu et al. ${ }^{11}$ The reason for the lack of correlation of Gensini score could be because the patients who had greater severity of CAD and higher Gensini score may have had more left ventricular dysfunction causing abnormal ventricular contours, resulting in redistribution of epicardial adipose tissue.

This study is unique in that CIMT and EAT thickness, two putative non-invasive markers of CAD- one old and one newwas evaluated in a population of suspected CAD patients with coronary risk factors in its ability to predict the presence or absence of significant epicardial coronary obstructive disease. We found that CIMT was unable to differentiate the presence of significant CAD whereas EAT thickness was significantly higher in the CAD patients.

\section{CONCLUSION}

- Epicardial fat thickness is significantly higher in patients with epicardial obstructive CAD in comparison to patients with normal epicardial coronary arteries.

- Carotid intima-media thickness is similar in patients with epicardial obstructive CAD and patients with normal epicardial coronary arteries.

- Epicardial fat thickness, but not CIMT, can differentiate patients with CAD among a population of patients with coronary risk factors and suspected CAD. Epicardial fat thickness did not increase with increasing severity of CAD.

- Epicardial fat thickness is related to age, BMI, waist circumference and lipid parameters.

\section{REFERENCES}

[1] Rosamond W, Flegal K, Furie K, et al. Heart disease and stroke statistics--2008 update: a report from the American Heart Association Statistics Committee and Stroke Statistics Subcommittee. Circulation 2008;117(4):e25-146.

[2] Gordon T, Kannel WB, Hjortland MC, et al. Menopause and coronary heart disease. The Framingham Study. Ann Intern Med 1978;89(2):157-61.

[3] Gupta R, Gupta VP, Ahluwalia NS. Educational status, coronary heart disease and coronary risk factor prevalence in a rural population of India. BMJ 1994;309(6965):1332-6.

[4] Gupta R, Gupta VP, Sarna M, et al. Prevalence of coronary heart disease and risk factors in an urban Indian population: Jaipur Heart Watch-2. Indian Heart J 2002;54(1):59-66.

[5] Yusuf S, Hawken S, Ounpuu S, et al. Effect of potentially modifiable risk factors associated with myocardial infarction in 52 countries (the INTERHEART study): case-control study. Lancet 2004;364(9438):937-52.

[6] Anand SS, Yusuf S, Vuksan V, et al. Differences in risk factors, atherosclerosis, and cardiovascular disease between ethnic groups in Canada: the Study of Health Assessment and Risk in Ethnic groups (SHARE). Lancet 2000;356(9226):279-84.

[7] Lerner DJ, Kannel WB. Patterns of coronary heart disease morbidity and mortality in the sexes: a 26year follow-up of the Framingham population. Am Heart J 1986;111(2):383-90.

[8] Sitzer M, Markus HS, Mendall MA, et al. C-reactive protein and carotid intimal medial thickness in a community population. J Cardiovasc Risk 2002;9(2):97-103.

[9] Sacks HS, Fain JN. Human epicardial adipose tissue: a review. Am Heart J 2007;153(6):907-17.

[10] Bachar GN, Dicker D, Kornowski R, et al. Epicardial adipose tissue as a predictor of coronary artery disease in asymptomatic subjects. Am J Cardiol 2012;110(4):534-8.

[11] Eroglu S, Sade LE, Yildirir A, et al. Epicardial adipose tissue thickness by echocardiography is a marker for the presence and severity of coronary artery disease. Nutr Metab Cardiovasc Dis 2009;19(3):211-7. 
[12] Shetty R, Vivek G, Naha K, et al. Correlation of epicardial fat and anthropometric measurements in Asian-Indians: a community based study. Avicenna J Med 2012;2(4):89-93.

[13] Jeong JW, Jeong MH, Yun KH, et al. Echocardiographic epicardial fat thickness and coronary artery disease Circ J 2007;71(4):536-9.

[14] Nabati M, Saffar N, Yazdani J, et al. Relationship between epicardial fat measured by echocardiography and coronary atherosclerosis: a single-blind historical cohort study. Echocardiography 2013;30(5):505-11.

[15] Iacobellis G, Corradi D, Sharma AM. Epicardial adipose tissue: anatomic, biomolecular and clinical relationships with the heart. Nat Clin Pract Cardiovasc Med 2005;2(10):536-43.

[16] Ahn SG, Lim HS, Joe DY, et al. Relationship of epicardial adipose tissue by echocardiography to coronary artery disease. Heart 2008;94(3):e7. 